\title{
AN EFFICIENT AND GREEN PROTOCOL FOR THE ONE-POT SYNTHESIS OF 3-AMIDO-ALKYL-4-HYDROXYCOUMARIN DERIVATIVES BY CHOLINE CHLORIDE/UREA AS A DEEP EUTECTIC SOLVENT
}

\author{
Hamed ASADI, Hossein ANARAKI-ARDAKANI, ${ }^{*}$ Parviz TORABI and Narges TAHERI \\ Department of Chemistry, Mahshahr Branch, Islamic Azad University, Mahshahr, Iran
}

A green and highly efficient synthesis of some 3-amido-alkyl4-hydroxycoumarin derivatives by one-pot, three-component reaction of aryl aldehydes, 4-hydroxycoumarin, or 4hydroxy-6-methylpyran-1-one, and amides in deep eutectic solvent (DES) is reported. The DES system offers advantages in terms of environmental benign, biodegradable, short reaction times, and high yield. DES can be easily recovered and can be reused for other runs without any reduction in the activity.

\section{INTRODUCTION}

Modern synthetic design demands high efficiency in terms of minimization of synthetic steps together with maximization of complexity. ${ }^{1}$ One of the ways to fulfill these goals is the development and use of multi-component reactions which consist of several simultaneous bondforming reactions and allow the high efficient synthesis of complex molecules starting from simple substrates in a one-pot manner. ${ }^{2-4}$

A new generation of green solvents, namely deep eutectic solvents (DESs) had emerged an environmentally-benign media alternative to hazardous organic solvent in a variety of applications. ${ }^{5-7}$ Deep eutectic solvent is defined as a mixture of two or more components that are capable of self-association through hydrogen-bond interactions, which result a large melting-point depression at a particular composition (the eutectic composition). ${ }^{8}$

DESs have some advantages, such as low price, negligible vapor pressure, non-flammability, simple reaction workup, low volatility, biodegradability and renewability. DESs are widely used in electrochemical applications and are promising alternatives for common organic solvents in industrial applications. ${ }^{9,10}$

Recently, we reported the reaction of 4-hydroxycoumarin, aromatic aldehydes, and acetonitrile in the presence of chlorosulfonic acid to produce 3-acetamido-alkyl-4-hydroxycoumarin derivatives. $^{11,12}$ also we reported the reaction of 4-hydroxycoumarin, aromatic aldehydes and amides in the presence $p$-toluene sulfonic acid and $\mathrm{ZnO} \mathrm{NPs}$ in solvent-free conditions to produce 
3-( $\alpha$-amidobenzyl)-4-hydroxycoumarin derivatives, ${ }^{13,14}$ but these methodologies have been associated with some short comings such as long reaction times, and difficulty in recovery and reusability of the catalysts.

Considering the above reports and in continuation of our research on multi-component reactions, ${ }^{15,16}$ herein, we report an efficient approach for one-pot synthesis of 3-amido-alkyl-4hydroxycoumarin derivatives $\mathbf{4}$ by a threecomponent reaction of 4-hydroxycoumarin, or 4-hydroxy-6-methylpyran-1-one 1, aromatic aldehydes $\mathbf{2}$ and amides $\mathbf{3}$, in the presence of deep eutectic solvent system based on choline chloride/urea (DES) as green and reusable catalyst in high yields (Scheme 1).

\section{EXPERIMENTAL}

\section{Materials and methods}

Products were characterized by comparison of their spectroscopic data (NMR and IR) and physical properties with those reported in the literature. Melting points were determined with an Electrothermal 9100 apparatus. Elemental analyses were performed using a Heraeus CHN-O-Rapid analyzer. Mass spectra were recorded on a FINNIGAN-MAT 8430 mass spectrometer operating at an ionization potential of $70 \mathrm{eV}$. IR spectra were recorded on a Shimadzu IR-470 spectrometer. ${ }^{1} \mathrm{H}$ and ${ }^{13} \mathrm{C}$ NMR spectra were recorded on Bruker DRX-500 Avance spectrometer at solution in DMSO- $\mathrm{d}_{6}$ using TMS as internal standard. Chemicals used in this work were purchased from Fluka (Buchs, Switzerland) and were used without further purification. Yields refer to isolated pure products.

\section{Preparation of choline chloride-based deep eutectic solvents}

Choline chloride-based deep eutectic solvents were prepared according to the literature ${ }^{17,18}$ and were used without further purification.

\section{General procedure}

A mixture of 4-hydroxycoumarin $(0.25 \mathrm{mmol})$, aromatic aldehyde $(0.25 \mathrm{mmol})$, and amide $(0.25 \mathrm{mmol})$ were added to choline chloride/urea $(1 \mathrm{~mL})$. The resulting mixture was stirred and heated $80{ }^{\circ} \mathrm{C}$ for $90-105 \mathrm{~min}$. (Table 2). After reaction completion, (TLC, ethyl acetate/n-hexane, 2:1), the reaction mixture was washed with water $(10 \mathrm{~mL})$ and the solid residue recrystallized from ethanol to obtain the pure product. All the products identified by IR, ${ }^{1} \mathrm{H}$ NMR and ${ }^{13} \mathrm{C}$ NMR spectral data and by comparison of their melting points with literature reports.

The spectral and analytical data for the new compounds are as following:
$\mathrm{N}$-((4-chlorophenyl) (4-hydroxy-2-oxo-2H-chromen-3-yl) methyl) benzamide (4h):

White powder, m.p. $189-191^{\circ} \mathrm{C}, \mathrm{IR}(\mathrm{KBr})\left(v_{\max } \mathrm{cm}^{-1}\right)$ : $3171(\mathrm{NH}), 1663,1620,(2 \mathrm{C}=\mathrm{O})$.

${ }^{1} \mathrm{H}$ NMR $\left(300 \mathrm{MHz}, \mathrm{CDCl}_{3}\right): \delta=6.04(1 \mathrm{H}, \mathrm{s}, \mathrm{CH}), 6.20(1 \mathrm{H}$, broad, NH), 7.13-8.04 (13 H, m, Ar), 11.35(1 H, broad, OH). ${ }^{13} \mathrm{C}$ NMR $\left(62.90 \mathrm{MHz}, \mathrm{CDCl}_{3}\right): \delta=35.80(\mathrm{CH}), 93.35$, $116.64,124.40,124.96,17.33,127.96,128.60,128.75$, $131.96,132.71,133.00,133.38,133.88,141.45,152.41$, 154.32 (carbons of $\mathrm{Ar}), 164.67,169.53(2 C=\mathrm{O})$. Anal. Calcd. for $\mathrm{C}_{23} \mathrm{H}_{16} \mathrm{ClNO}_{4}$ : $\mathrm{C}, 68.07 ; \mathrm{H}, 3.97 ; \mathrm{N}, 3.45 \%$. Found: $\mathrm{C}$, $68.21 ; \mathrm{H}, 3.81 ; \mathrm{N}, 3.58 \%$.

$\mathrm{N}$-((4-hydroxy-2-oxo-2H-chromen-3-yl)(4-

methoxyphenyl)methyl)propionamide (4i):

White powder, m.p. $187-189^{\circ} \mathrm{C}$, IR $(\mathrm{KBr})\left(v_{\max } \mathrm{cm}^{-1}\right)$ : $3348(\mathrm{NH}), 1682,1619,(2 \mathrm{C}=\mathrm{O})$.

${ }^{1} \mathrm{H}$ NMR (300 MHz, d $\mathrm{d}_{6}$-DMSO): $\delta=0.92\left(3 \mathrm{H}, \mathrm{t}, J_{\mathrm{HH}}=7.6 \mathrm{H}_{\mathrm{Z}}\right.$ $\left.\mathrm{CH}_{3}\right), 2.26\left(2 \mathrm{H}, \mathrm{q}, \mathrm{J}_{\mathrm{HH}}=7.6 \mathrm{H}_{\mathrm{Z}}, \mathrm{CH}_{2}\right), 3.65\left(3 \mathrm{H}, \mathrm{s}, \mathrm{OCH}_{3}\right)$, $6.08(1 \mathrm{H}$, broad, $\mathrm{CH}), 6.28(1 \mathrm{H}$, broad, $\mathrm{NH}), 7.20-8.05(8 \mathrm{H}$, $\mathrm{m}, \mathrm{Ar}), 10.34\left(1 \mathrm{H}\right.$, broad, OH). ${ }^{13} \mathrm{C} \mathrm{NMR}\left(75 \mathrm{MHz}, \mathrm{d}_{6}-\right.$ DMSO): $\delta=10.22\left(\mathrm{CH}_{3}\right), 28.69\left(\mathrm{CH}_{2}\right), 47.38(\mathrm{CH}), 106.72$, $116.62,116.68,124.30,124.51,126.51,126.98,128.22$, 132.87, 141.08, 152.80, 161.87 (carbons of Ar), 162.36, $174.34(2 C=\mathrm{O})$. ). Anal. Calcd. for $\mathrm{C}_{20} \mathrm{H}_{19} \mathrm{NO}_{5}$ : C, 67.98; $\mathrm{H}$, 5.42; N, 3.96\%. Found: C, 67.74; H, 5.61; N, 4.04\%.

2-oxo-2H-pyran-3-yl) methyl) acetamide (4j):

White powder, m.p. $177-179^{\circ} \mathrm{C}$, IR $(\mathrm{KBr})\left(v_{\max } \mathrm{cm}^{-1}\right)$ : $3103(\mathrm{NH}), 1680,1636$, (2 $\mathrm{C}=\mathrm{O})$. ). ${ }^{1} \mathrm{H}$ NMR (300 MHz, $\left.\mathrm{CDCl}_{3}\right): \delta=2.20\left(3 \mathrm{H}, \mathrm{s}, \mathrm{CH}_{3}\right), 2.30\left(3 \mathrm{H}, \mathrm{s}, \mathrm{CH}_{3}\right), 5.69(1 \mathrm{H}, \mathrm{s}$, $\mathrm{CH}), 5.97(1 \mathrm{H}, \mathrm{s}, \mathrm{CH}=\mathrm{C}), 6.07(1 \mathrm{H}$, broad, $\mathrm{NH}), 7.06-7.28$ $(4 \mathrm{H}, \mathrm{m}, \mathrm{Ar}), 10.94(1 \mathrm{H}$, broad, $\mathrm{OH}) .{ }^{13} \mathrm{C}$ NMR $(75 \mathrm{MHz}$, $\left.\mathrm{CDCl}_{3}\right): \delta=19.66\left(\mathrm{CH}_{3}\right), 22.05\left(\mathrm{CH}_{3}\right), 34.40(\mathrm{CH}), 103.35$, $127.90,128.60,132.49,134.05,152.38,158.60$ (carbons of Ar), 162.04, $170.10(2 \mathrm{C}=\mathrm{O})$. Anal. Calcd. for $\mathrm{C}_{15} \mathrm{H}_{14} \mathrm{ClNO}_{4}$ : C, 58.55; H, 4.59; N, 4.55\%. Found: C, 58.68; H, 4.64; N, $4.39 \%$.

$\mathrm{N}$-((4-chlorophenyl) (4-hydroxy-6-methyl-

$\mathrm{N}$-((4-chlorophenyl) (4-hydroxy-6-methyl-2-oxo-2H-pyran-3yl) methyl) benzamide (4k):

White powder, m.p. $179-181^{\circ} \mathrm{C}, \mathrm{IR}(\mathrm{KBr})\left(v_{\max } \mathrm{cm}^{-1}\right)$ : $3300(\mathrm{NH}), 1679,1619(2 \mathrm{C}=\mathrm{O}) .{ }^{1} \mathrm{H}$ NMR $(300 \mathrm{MHz}$, $\left.\mathrm{CDCl}_{3}\right): \delta=2.27\left(3 \mathrm{H}, \mathrm{s}, \mathrm{CH}_{3}\right), 5.74(1 \mathrm{H}, \mathrm{s}, \mathrm{CH}), 6.06(1 \mathrm{H}, \mathrm{s}$, $\mathrm{CH}=\mathrm{C}), 6.25(1 \mathrm{H}$, broad, $\mathrm{NH}), 7.06-7.87(8 \mathrm{H}, \mathrm{m}, \mathrm{Ar}), 10.94(1$ $\mathrm{H}$, broad, $\mathrm{OH}) .{ }^{13} \mathrm{C} \mathrm{NMR}\left(75 \mathrm{MHz}, \mathrm{CDCl}_{3}\right): \delta=19.62\left(\mathrm{CH}_{3}\right)$, $34.33(\mathrm{CH})$, 99.70, 101.56, 127.35, 127.91, 128.58, 132.02, $132.44,133.24,134.25,144.34,152.54,158.90$ (carbons of Ar), 161.77, $169.67(2 \mathrm{C}=\mathrm{O})$. Anal. Calcd. for $\mathrm{C}_{20} \mathrm{H}_{16} \mathrm{ClNO}_{4}$ : C, 64.96; H, 4.36; N, 3.79\%. Found: C, 64.82; H, 4.45; N, $3.86 \%$.

$\mathrm{N}$-((4-hydroxy-6-methyl-2-oxo-2H-pyran-3-

yl)(phenyl)methyl)benzamide (4I):

White powder, m.p. $176^{\circ} \mathrm{C}$, IR $(\mathrm{KBr})\left(v_{\max } \mathrm{cm}^{-1}\right): 3339$ (NH), 1682,1628 (2 $\mathrm{C}=\mathrm{O}) .{ }^{1} \mathrm{H}$ NMR $\left(300 \mathrm{MHz}, \mathrm{CDCl}_{3}\right)$ : $\delta=2.17\left(3 \mathrm{H}, \mathrm{s}, \mathrm{CH}_{3}\right), 5.79(1 \mathrm{H}, \mathrm{s}, \mathrm{CH}), 6.12(1 \mathrm{H}, \mathrm{s}, \mathrm{CH}=\mathrm{C})$, 6.25 $(1 \mathrm{H}$, broad, $\mathrm{NH}), 7.06-7.86(10 \mathrm{H}, \mathrm{m}, \mathrm{Ar}), 11.02(1 \mathrm{H}$, broad, $\mathrm{OH}) \cdot{ }^{13} \mathrm{C}$ NMR $\left(75 \mathrm{MHz}, \mathrm{CDCl}_{3}\right): \delta=19.54\left(\mathrm{CH}_{3}\right)$, $34.21(\mathrm{CH}), 99.72,102.32,127.33,128.01,128.65,132.06$, $132.34,133.29,134.17,144.32,152.50,157.96$ (carbons of Ar), 161.83, $169.82(2 \mathrm{C}=\mathrm{O})$. Anal. Calcd. for $\mathrm{C}_{19} \mathrm{H}_{16} \mathrm{NO}_{4}: \mathrm{C}$, $70.80 ; \mathrm{H}, 5.00 ; \mathrm{N}, 4.35 \%$. Found: C, 70.65; H, 5.17; N, $4.43 \%$. 
<smiles>[Y]C(N)=O</smiles><smiles>[X]C(=O)NC([Al])C1=C(O)C[Y]OC1=O</smiles><smiles>[Y17]CC(C)=CCC12CC3CCC(CC(C3)C1)C2</smiles>

$\mathrm{X}=\mathrm{CH}_{3}, \mathrm{C}_{2} \mathrm{H}_{5}, \mathrm{Ph}$

Scheme 1 - Synthesis of 3-amido-alkyl-4-hydroxycoumarin derivatives in DES as solvent and catalyst.

\section{RESULTS AND DISCUSSION}

At first, the reaction 4-hydroxycoumarin, benzaldehyde and acetamide were selected as model reaction. The model reaction was carried in various choline chloride $(\mathrm{ChCl})$ - based DESs system like ChCl:PTSA, ChCl: $\mathrm{ZnCl}_{2}, \mathrm{ChCl}$ :urea, $\mathrm{ChCl}$ : citric acide and $\mathrm{ChCl}$ :Oxalic acid in different temperatures and the results are listed in Table 1. As indicated, the best yield was obtained in choline chloride and urea at $80{ }^{\circ} \mathrm{C}$ (Table 1 , entry 7). A decrease in temperature gave lower yields (entry 6), and in the absence of the DES, only a $25 \%$ yield of the product was obtained (entry 5).

Table 1

Optimization of reaction in various choline chloride-based $\mathrm{DES}_{\mathrm{S}}{ }^{\mathrm{a}}$

\begin{tabular}{c|c|c|c|c}
\hline Entry & DES & Temp $\left({ }^{\mathbf{} C}\right)$ & Time (min) & Yield (\%) $^{\mathbf{a}}$ \\
\hline $\mathbf{1}$ & Choline chloride:ZnCl $(1: 2)$ & 80 & 180 & 45 \\
$\mathbf{2}$ & Choline chloride:PTSA(1:1) & 80 & 180 & 40 \\
$\mathbf{3}$ & Choline chloride:citric acide(1:1) & 80 & 180 & 45 \\
$\mathbf{4}$ & Choline chloride:oxalic acid(1:1) & 90 & 180 & 55 \\
$\mathbf{5}$ & -- & 100 & 240 & 25 \\
$\mathbf{6}$ & Choline chloride:urea(1:2) & 60 & 95 & 80 \\
$\mathbf{7}$ & Choline chloride:urea(1:2) & 80 & 95 & 90 \\
$\mathbf{8}$ & Choline chloride:urea(1:2) & 100 & 95 & 90 \\
\hline
\end{tabular}

${ }^{\mathrm{b}}$ Isolated yield.

a Reaction condition: 4-hydroxycoumarin, $(0.25 \mathrm{mmol})$, benzaldehyde $(0.25 \mathrm{mmol})$ and acetamide $(0.25 \mathrm{mmol})$ in DES $(1 \mathrm{~mL})$.

\section{Table 2}

Three-component reaction of aryl aldehydes, 4-hydroxycoumarin or 4-hydroxy-6-methylpyran-1-one and amides in deep eutectic solvent (DES)

\begin{tabular}{|c|c|c|c|c|c|c|}
\hline Entry & Substrate & Ar & $\mathbf{X}$ & Time(min) & Yield(\%) & $\mathbf{m p}{ }^{\circ} \mathrm{C}$ \\
\hline $4 a$ & & $\mathrm{C}_{6} \mathrm{H}_{5}$ & $\mathrm{CH}_{3}$ & 95 & 90 & $184(184-186)^{[13-14]}$ \\
\hline & & $4-\mathrm{Cl}-\mathrm{C}_{6} \mathrm{H}_{4}$ & $\mathrm{CH}_{3}$ & 100 & 92 & $176(175-177)^{[13-14]}$ \\
\hline $4 c$ & $\mathrm{OH}$ & $4-\mathrm{Br}-\mathrm{C}_{6} \mathrm{H}_{4}$ & $\mathrm{CH}_{3}$ & 100 & 90 & $172-175(172-174)^{[13-14]}$ \\
\hline
\end{tabular}


Table 2 (continued)

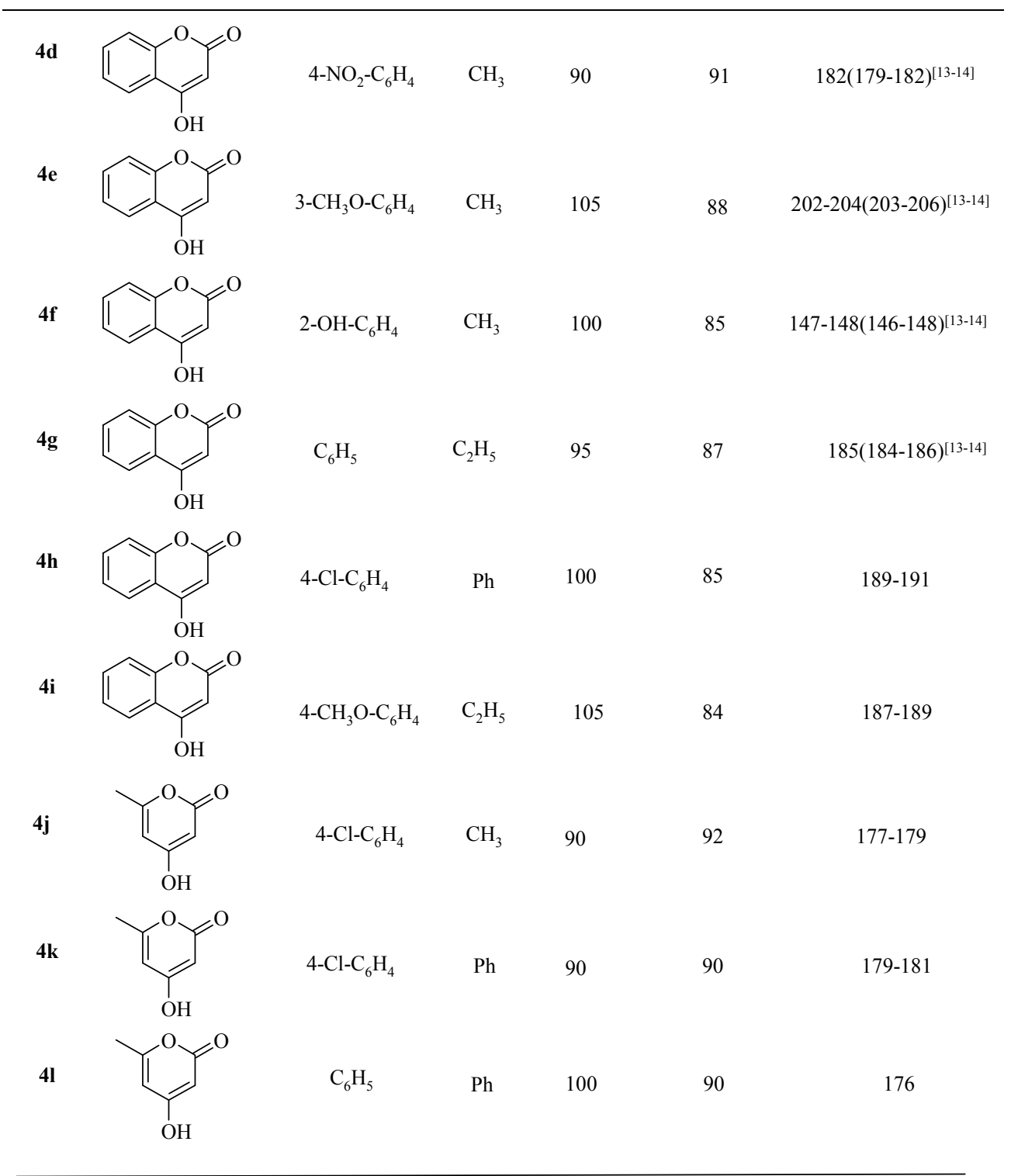

To study the scope and limitations of the reaction, various aromatic aldehydes, cyclic 1,3diketone and amides were employed. The results are shown in Table 2. In all cases, aromatic aldehydes substituted with either electron-donating or electron-withdrawing groups underwent the reaction smoothly and gave the products in good yields (Table 2).

Compounds $4 \mathbf{h}-\mathbf{l}$ were new and their structures were deduced by elemental and spectral analysis. Other compounds (4a-g) were known and their structures were deduced by comparison of melting points and spectral data with authentic samples. ${ }^{13,14}$

The suggested mechanism for the formation of the products is shown in Scheme 2. The reaction of 4-hydroxycoumarin with aromatic aldehyde in the presence of DES is proposed to give 3-benzylidine-chroman-2,4-diones.Then 3-benzylidine-chroman-2,4-diones, generated in situ, react with amide to form the 3-acetamido-alkyl-4hydroxycoumarin products, DES activates all carbonyl groups via hydrogen bonding (Scheme 2).

The reusability of the catalyst for the synthesis of $\quad \mathrm{N}$-((4-hydroxy-2-oxo-2H-chromen-3yl)(phenyl)methyl)acetamide(4a) was investigated (Figure1). The DES was recovered from the aqueous phase by evaporation at $80{ }^{\circ} \mathrm{C}$ under vacuum and tested for its activity in the subsequent run was recycled for the next reaction. DES was tested for 4 runs. It was seen that the catalyst activity displayed very good reusability (Figure 1). 

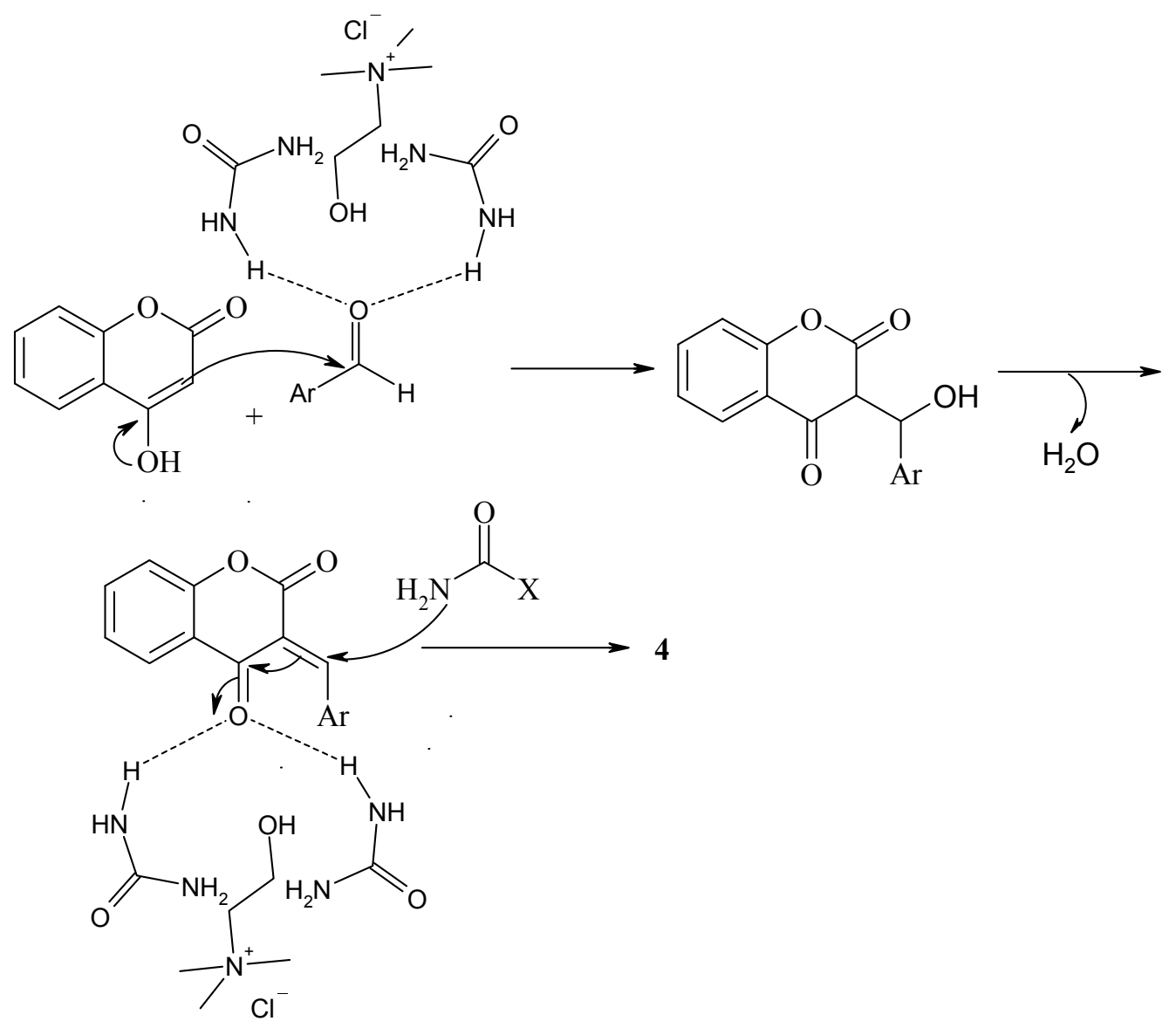

Scheme 2 - Suggested pathway for the formation of compounds 4a-l.

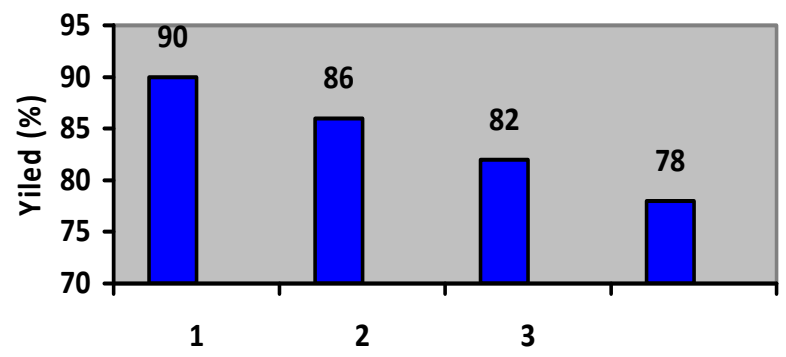

Run No.

Fig. 1 - Reusability of the DES.

Table 3

Comparison of different methodology for the synthesis of compound $4 \mathbf{a}$

\begin{tabular}{|c|c|c|c|c|c|}
\hline Entry & Conditions & Temp $\left({ }^{\circ} \mathrm{C}\right)$ & Time(min) & 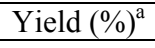 & Ref \\
\hline 1 & P-TSA (5 mol\%), Solvent-free & 115 & 300 & 85 & {$[13]$} \\
\hline 2 & ZnO NP, Solvent-free & 110 & 130 & 85 & {$[14]$} \\
\hline 3 & This work & 80 & 95 & 90 & - \\
\hline
\end{tabular}

\footnotetext{
${ }^{\mathrm{a}}$ Isolated yield.
} 
Finally, in order to access the efficiency and generality of this methodology, we compared this method with previous reported catalysts in the synthesis of compound 4a (Table 3). From comparison with the results depicted in Table 3, it was found that DES is the most efficient catalyst with respect to reaction times, temperature, yield of the products and reusability of the catalyst.

\section{CONCLUSIONS}

In conclusion, we have successfully developed a simple and efficient methodology for the synthesis of 3-amido-alkyl-4-hydroxycoumarin derivatives by the three-component reaction of aryl aldehydes, 4hydroxycoumarin, or 4-hydroxy-6-methylpyran-1one, and amides in the present of deep eutectic mixture as green catalyst/solvent. Prominent among the advantages of this method are operational simplicity, mild reaction condition, short reaction times, higher yields, safe environmentally, also inexpensive and recyclable nature of DES.

Acknowledgements. We are thankful to the Islamic Azad University, Mahshahr branch, for the support of this work.

\section{REFERENCES}

1. B. M. Trost, Science, 1991, 254, 1471-1477.

2. H. Bienayme, C. Hulme, G. Oddon and P. Schmidt, Chem. Eur. J., 2000, 6, 3321-3329.

3. A. J. Von Wangelin, H. Neumann, D. Gördes, S. Klaus, D Strübing, M. Beller, Chem. Eur. J., 2003, 9, 4286-4294.

4. R. V. A. Orru and M. de Greef, Synthesis, 2003, 1471-1499.

5. Y. Cui, C. Li, J. Yin, S. Li, Y. Jia and M. Bao, J. Mol. Liq., 2017, 236, 338-343.

6. Q. Zhang, K. De. Oliveira Vigier, S. Royer and F. Jerome, Chem. Soc. Rev., 2012, 41, 7108-7145.

7. N. Azizi, T. Soleymani Ahooi, M. Mahmoudi Hashemi, J. Molec. Liquids, 2017, 246, 221-224.

8. P. Liu, J.-W. Hao, L.-P. Mo and Z.-H. Zhang, RSC Adv., 2015, 5, 48675-48704.

9. M. Francisco, A. Van den Bruinhorst and M. C. Kroon, Angew Chem Int Ed., 2013, 52, 3074-3085.

10. A. Shaabani, S. E. Hooshmand and A. T. Tabatabaei, Tetrahedron Lett., 2016, 57, 351-353.

11. M. Anary-Abbasinejad, H. Anaraki-Ardakani, A. Saidipoor and M. Shojaee, J. Chem. Res., 2007, 535-537.

12. M. Anary-Abbasinejad, H. Anaraki-Ardakani and A. Hassanabadi, Synth. Commun., 2008, 38, 3706-3716.

13. M. Malekpour, H. Anaraki-Ardakani and M. Noei, $J$. Chem. Research., 2012, 11, 715-717.

14. H. Anaraki-Ardakani and A. Charooseai, Oriental J. Chem., 2015, 3, 1455-1460.

15. H. Anaraki-Ardakani, Russ. J. General Chem., 2017, 87, 1820-1825.

16. H. Anaraki-Ardakani and P. Nikomanesh, Iran. J. Chem. Chem. Eng., 2017, 36, 17-22.

17. A. P. Abbott, D. Boothby, G. Capper, D. L. Davies and R. K. Rasheed, J. Am. Chem. Soc., 2004, 126, 9142-9147.

18. A. P. Abbott, G. Capper, D. L. Davies, R. K. Rasheed and V. Tambyrajah, Chem. Commun., 2003, 70-17. 